\title{
Relation Model of Soil Nutrients and Tobacco Quality Based on Principal Component and Regression Analysis
}

\author{
Houli $\mathrm{Hu}$, Jiande $\mathrm{Wu}^{*}$, Xiaodong Wang \\ Faculty of Information Engineering and Automation \\ Kunming University of Science and Technology \\ Kunming 650500, China \\ xiaoli01030@126.com
}

\author{
Kuake Huang \\ Qujing Branch, Yunnan Tobacco Company \\ Kunming 655000, China
}

\begin{abstract}
In order to study the relationship of tobacco soil nutrients and chemical indicators, principal component analysis and stepwise regression analysis were used to establish the relation model between soil nutrients and tobacco quality. In the first, discussing the correlation of soil nutrients and the major tobacco chemical composition; Then, using principal component analysis to analyze the impact of factors of the leaf chemical indicators, eliminated the intrinsic link and repeat information between properties, and extracting the principal component which strong influence on the chemical composition of tobacco; And finally stepwise regression analysis was used to established the equation between soil nutrients and tobacco chemical components.
\end{abstract}

Keywords- principal component analysis; stepwise regression analysis; soil nutrients; Tobacco quality

\section{INTRODUCTION}

Soil is the base of planting tobacco and the nutrient sources for tobacco, it directly impact on the growth and nutrition levels of tobacco, thereby affecting the yield and quality of tobacco, the suitable soil conditions is an important foundation for the production of quality tobacco ${ }^{[1]}$. Therefore, the study of relationship between nutrients in the soil and leaf quality and clear of the quantitative level between them, it can provide a scientific basis to improve tobacco soil environment, enhance quality leaf and foster high-quality tobacco.

It is a complex multi-factor multivariable problem to soil nutrient effects on plant nutrition ${ }^{[2]}$. On such issues, the popular ways are simple regression analysis and correlation analysis in the past ${ }^{[3-5]}$, these methods only examine the relationships between a number of variables and a certain variable, they reflect neither the internal relationship between a whole set of variables with another whole set of variables, nor able to clearly explain relationships between the Internal variable groups or external groups ${ }^{[6]}$. On analysis of soil nutrient and chemical components of tobacco, we often need to create a relationship model between variables affecting chemical indicators and chemical composition variables. General multivariate linear regression model in a high degree of correlation between the independent variables, and it has a serious multi commonality, thus it will affect the model fitting goodness. Principal component analysis (PCA) is a statistical method which is the study of the multiple indicators converted to fewer composite indicators, and it is the result of linear transformation and discards some of the information and high-dimensional variable space to reduce the dimension, the relevant process variables compressed to a few independent variables. It also reflected the original information of multiple variables ${ }^{[7]}$. The method of combining Principal component analysis and stepwise regression analysis not only can reduce the number of variables, but also solve the problem of multiple common.

This article is a correlation analysis between soil nutrient and chemical composition of the tobacco sample in Yunnan seven tobacco growing areas, it aimed at in-depth understanding of how the soil nutrients to affect the chemical composition. By using the method of combining Principal component analysis and stepwise regression analysis, it not only reduce the number of variables, solve the problem of multiple common, but also establish a relational model between soil nutrient and chemical composition of tobacco, which provide a scientific basis for planting the high-quality tobacco.

\section{SOURCES AND DETERMinAtion Of SAMPLE}

\section{A. Sources of samples}

Samples are taken from the tobacco growing areas of Yunnan Luliang, Qilin District, Shizong, Fuyuan, Malong, Zhanyi, Huize, where the tobacco leaves grows on three different types of soil and its corresponding root zone soil. Flue-cured tobacco samples selected local cultivars, using fixed-grade, fixed leaf sampling method, samples were collected 59 from the middle of tobacco leaves.

\section{B. Maintaining the Integrity of the Specifications}

(1) Determination of soil sample determination of soil samples including $\mathrm{PH}$ value, organic matter, total $\mathrm{N}$, total $\mathrm{P}$, and total K, Hydrolytic N, Available P, Available K of eight indicators. Determination of soil nutrients specifically refer to the literature ${ }^{[8]}$.

(2) Determination of tobacco sample determination of tobacco samples including the total sugar, reducing sugar, total N, nicotine, potassium, chloride, starch of seven indicators. Determination of Chemical composition indicators of tobacco refer to the literature ${ }^{[9]}$. 
C. The data processing

a statistical method is defined as by SPSS17.0 statistical software, using principal component analysis and stepwise regression analysis as a statistical method.

\section{RESUltS AND ANALYSIS}

A. Test data descriptive statistics and related analysis

The selected eight indicators of soil nutrients and seven tobaccos leave chemical composition of the raw data for statistical to analysis the results described in Table 1.

TABLE I. TOBACCo RAW DATA FOR MODELING DESCRIPTIVE STATISTICS

\begin{tabular}{|c|c|c|c|c|c|c|c|}
\hline Index & Minimm & Maxima & Mean & $\begin{array}{l}\text { Standard } \\
\text { deviation }\end{array}$ & $\begin{array}{c}\text { Coefficient of } \\
\text { variation (\%) }\end{array}$ & Skewness & Kurtosi \\
\hline PH & 4.39 & 7.58 & 6.203 & 0.750 & 12.091 & -0.176 & -0.577 \\
\hline Organic matter $/ \%$ & 1.38 & 6.07 & 3.613 & 0.972 & 26.903 & -0.227 & -0.228 \\
\hline Total N (mg/kg) & 0.064 & 0.351 & 0.176 & 0.047 & 26.705 & 0.848 & 2.707 \\
\hline Total P (mg/kg) & 0.036 & 0.254 & 0.106 & 0.041 & 38.679 & 0.951 & 1.550 \\
\hline Total K (mg/kg) & 0.160 & 2.658 & 0.798 & 0.510 & 63.910 & 1.338 & 2.103 \\
\hline Hydrolytic N (mg/kg) & 57.58 & 205.10 & 126.084 & 31.667 & 25.116 & 0.041 & -0.277 \\
\hline Available P(mg/kg) & 7.58 & 84.45 & 28.543 & 17.661 & 61.875 & 1.253 & 1.176 \\
\hline Available K(mg/kg) & 38.10 & 350.13 & 151.269 & 72.288 & 47.788 & 0.576 & -0.170 \\
\hline Total sugar /\% & 19.33 & 39.98 & 30.421 & 4.278 & 14.063 & -0.344 & -0.113 \\
\hline Deoxidize sugar /\% & 11.64 & 30.53 & 22.221 & 4.151 & 18.681 & 0.063 & -0.266 \\
\hline $\mathrm{N} / \%$ & 0.94 & 3.15 & 1.946 & 0.378 & 19.424 & 0.240 & 0.982 \\
\hline Nicotine /\% & 1.12 & 3.66 & 2.156 & 0.614 & 28.479 & 0.304 & -0.840 \\
\hline $\mathrm{K} / \%$ & 1.09 & 2.23 & 1.605 & 0.276 & 17.196 & 0.172 & -0.734 \\
\hline $\mathrm{Cl} / \%$ & 0.05 & 1.14 & 0.273 & 0.241 & 88.278 & 1.616 & 2.870 \\
\hline Starch /\% & 1.00 & 5.73 & 2.960 & 1.074 & 36.284 & 0.419 & -0.113 \\
\hline
\end{tabular}

TABLE II. The CORRELATION MATrix BETWEen SOIL Nutrients AND TOBACCO ChEMICAl COMPO

\begin{tabular}{|c|c|c|c|c|c|c|c|c|c|c|c|c|c|c|}
\hline & $P H$ & $\begin{array}{c}\text { Organic } \\
\text { matter }\end{array}$ & $\begin{array}{r}\text { Total } \\
N\end{array}$ & $\begin{array}{r}\text { Total } \\
P\end{array}$ & $\begin{array}{r}\text { Total } \\
K\end{array}$ & $\begin{array}{l}\text { Hydro- } \\
\text { lytic } N\end{array}$ & $\begin{array}{l}\text { Avail- } \\
\text { able p }\end{array}$ & $\begin{array}{l}\text { Avail- } \\
\text { able } k\end{array}$ & $\begin{array}{r}\text { total } \\
\text { sugar }\end{array}$ & $\begin{array}{r}\text { deoxidize } \\
\text { sugar }\end{array}$ & $N$ & nicotine & $K$ & Cl starch \\
\hline PH & 1.000 & & & & & & & & & & & & & \\
\hline Organic matter & -0.167 & 1.000 & & & & & & & & & & & & \\
\hline Total N & 0.033 & 0.799 & 1.000 & & & & & & & & & & & \\
\hline Total P & -0.029 & 0.374 & 0.372 & 1.000 & & & & & & & & & & \\
\hline Total K & 0.322 & -0.203 & 0.024 & -0.230 & 1.000 & & & & & & & & & \\
\hline Hydrolytic N & -0.399 & 0.909 & 0.722 & 0.336 & -0.208 & 1.000 & & & & & & & & \\
\hline Available P & -0.064 & -0.107 & -0.023 & 0.354 & -0.021 & -0.142 & 1.000 & & & & & & & \\
\hline Available k & -0.042 & 0.310 & 0.313 & 0.432 & 0.057 & 0.280 & 0.390 & 1.000 & & & & & & \\
\hline total sugar & -0.029 & -0.148 & -0.103 & 0.218 & 0.057 & -0.015 & 0.277 & 0.037 & 1.000 & & & & & \\
\hline deoxidize sugar & -0.050 & -0.126 & -0.170 & 0.098 & 0.024 & 0.043 & 0.009 & -0.105 & 0.819 & 1.000 & & & & \\
\hline $\mathbf{N}$ & -0.075 & 0.271 & 0.206 & -0.032 & -0.288 & 0.142 & -0.033 & 0.092 & -0.647 & -0.690 & 1.000 & & & \\
\hline nicotine & 0.128 & 0.044 & 0.142 & 0.160 & 0.020 & -0.165 & 0.276 & 0.142 & -0.440 & -0.597 & 0.587 & 1.000 & & \\
\hline $\mathbf{K}$ & -0.215 & 0.012 & 0.010 & -0.276 & 0.112 & 0.133 & -0.254 & -0.117 & -0.312 & -0.165 & 0.021 & -0.245 & 1.000 & \\
\hline Cl & 0.080 & 0.112 & 0.155 & -0.073 & 0.125 & -0.047 & 0.011 & 0.080 & -0.080 & -0.141 & 0.216 & 0.148 & -0.243 & 1.000 \\
\hline starch & -0.138 & 0.073 & 0.019 & 0.285 & -0.124 & 0.173 & 0.116 & 0.020 & 0.594 & 0.504 & -0.502 & -0.241 & -0.266 & -0.1541 .000 \\
\hline
\end{tabular}


Indicated in Table 1, the variation of nutrient indicators was moderate intensity variation, in which the largest variability of, the smallest variability of total is $\mathrm{PH}$, explaining the difference is that total $\mathrm{K}$ content maximum, and the sample is relatively uniform $\mathrm{PH}$ in the selection of tobacco soil samples. In the selected leaf chemical indicators, tobacco total sugar, reducing sugar, total $\mathrm{N}, \mathrm{K}$ and other variation is relatively uniform, while $\mathrm{Cl}$ varied greatly.

Indicated in Table 2, the $\mathrm{PH}$ value of soil nutrients compared with nicotine showed a significant positive correlation; organic matter in soil nutrients with leaf chemical composition of total sugar, deoxidize sugar was a significantly negative correlation, and with total $\mathrm{N}, \mathrm{Cl}$ was a significant positive correlation; total $\mathrm{P}$, available $\mathrm{P}$ in soil nutrients with chemical composition of $\mathrm{K}$ was a significantly negative correlation, with other correlation was not significant; K, Hydrolytic N, available $\mathrm{K}$ in soil nutrients with chemical composition correlation is not significant. To further understand the relationship between the Yunnan tobacco leaf and tobacco soil nutrient quality, should think highly of the analysis of its principal component.

\section{B. Principal component extraction}

According to table 3 and table 4, we could find that the first three principal components of the cumulative contribution rate has reached $85.635 \%$, basically reflects the original variable information. The first principal component to the total variance contribution rate of $49.121 \%$, represents the organic matter, total $\mathrm{N}$, total $\mathrm{P}$, hydrolytic $\mathrm{N}$; The second principal component to the total variance contribution rate of $28.609 \%$, represents the available $\mathrm{P}$, available $\mathrm{K}$; The third principal component to the total variance contribution rate of $19.795 \%$, represents the $\mathrm{PH}$, total $\mathrm{K}$.

TABLE III. EIgENVALUES AND CUMULATIVE VARIANCE CONTRIBUTION RATE

\begin{tabular}{llll}
\hline $\begin{array}{l}\text { Main } \\
\text { ingredient }\end{array}$ & Eigenvalues & $\begin{array}{l}\text { Contribution } \\
\text { rate \% }\end{array}$ & $\begin{array}{l}\text { Cumulative } \\
\text { contribution rate \% }\end{array}$ \\
\hline $\mathbf{1}$ & 3.130 & 49.121 & 49.121 \\
$\mathbf{2}$ & 1.569 & 28.609 & 68.730 \\
$\mathbf{3}$ & 1.344 & 19.795 & 85.635 \\
\hline
\end{tabular}

TABLE IV. MAIN COMPONENT EIGENVECTORS

\begin{tabular}{cccc}
\hline & \multicolumn{3}{c}{ Main ingredient } \\
\cline { 2 - 4 } & 1 & 2 & 3 \\
\hline PH & -0.290 & 0.204 & 0.730 \\
Organic matter & 0.920 & -0.246 & 0.137 \\
Total N & 0.824 & -0.097 & 0.400 \\
Total P & 0.600 & 0.506 & -0.107 \\
Total K & -0.262 & 0.142 & 0.745 \\
Hydrolytic N & 0.908 & -0.319 & -0.018 \\
Available P & 0.089 & 0.838 & -0.236 \\
Available K & 0.511 & 0.614 & 0.104 \\
\hline
\end{tabular}

The principal component scores of samples of tobacco were calculated by the principal component eigenvectors and the original value of the variable, The first three principal components as a linear combination:

$$
\begin{aligned}
& \mathrm{Z} 1=-0.290 \mathrm{X}_{1}+0.920 \mathrm{X}_{2}+0.824 \mathrm{X}_{3}+0.600 \mathrm{X}_{4}-0.262 \mathrm{X}_{5}+0.908 \mathrm{X}_{6} \\
& +0.089 \mathrm{X}_{7}+0.511 \mathrm{X}_{8} \\
& \mathrm{Z} 2=0.204 \mathrm{X}_{1}-0.204 \mathrm{X}_{2}-0.097 \mathrm{X}_{3}+0.506 \mathrm{X}_{4}+0.142 \mathrm{X}_{5}-0.319 \mathrm{X}_{6} \\
& +0.838 \mathrm{X}_{7}+0.614 \mathrm{X}_{8} \\
& \mathrm{Z} 3=730 \mathrm{X}_{1}+0.137 \mathrm{X}_{2}+0.400 \mathrm{X}_{3}-0.107 \mathrm{X}_{4}+0.745 \mathrm{X}_{5}-0.018 \mathrm{X}_{6} \\
& -0.236 \mathrm{X}_{7}+0.104 \mathrm{X}_{8}
\end{aligned}
$$

\section{Regression model and F-test}

The tobacco chemical constituents of total sugar as the dependent variable and three principal components score as independent variables were to stepwise regression analysis. In accordance with the least principle of regression equation variable to select and build the regression models, the regression results of tobacco total sugar shown in Table 4. Similarly, you can also separately establish the regression model of reducing sugar, total $\mathrm{N}$, nicotine, $\mathrm{K}, \mathrm{Cl}$ and starch.

TABLE V. LINEAR REgRESSION RESULTS

\begin{tabular}{ccccc}
\hline $\begin{array}{r}\text { Constant and } \\
\text { Variable }\end{array}$ & Coefficient & $\begin{array}{r}\text { Standard } \\
\text { error }\end{array}$ & \multicolumn{1}{c}{$\boldsymbol{~}$} & Sig. \\
\hline Constant & 23.545 & 5.427 & 3.170 & 0.000 \\
$\mathbf{Z 1}$ & 4.840 & 1.384 & 10.577 & 0.000 \\
$\mathbf{Z 2}$ & 7.014 & 1.861 & 12.791 & 0.000 \\
$\mathbf{Z 3}$ & 5.751 & 2.721 & 2.536 & 0.000 \\
\hline
\end{tabular}

According to the results in Table 5 , a regression equation is as follows:

$\mathrm{Y}=4.840 \mathrm{Z} 1+7.014 \mathrm{Z} 2+5.751 \mathrm{Z} 3$, The equation correlation coefficient after correction is $R^{2}=0.505$. The equation for the establishment of the significance test, the test results of the regression equation was shown in Table 6.According to the Table 6 , we can find that he regression results is significant when $F=68.985>F_{0.05}\left(F_{0.05}=2.94\right)$, that it exists a significant linear statistical relationship between soil fertility elements and tobacco chemical components. As the Sig. $=0.000<0.05$, the results illustrate the probability of error is zero. Therefore, the equation is to be reliable.

TABLE VI. REGRESSION EQUATION F TEST

\begin{tabular}{crrcccc}
\hline & Squares & $\boldsymbol{d f}$ & $\begin{array}{c}\text { Mean } \\
\text { square }\end{array}$ & $\boldsymbol{F}$ & $\boldsymbol{F}_{0.05}$ & Sig. \\
\hline Regression & 78.518 & 3 & 26.173 & 68.985 & 2.94 & 0.000 \\
Residuals & 113.355 & 53 & 2.139 & & & \\
Total & 191.873 & 56 & & & & \\
\hline
\end{tabular}




\section{CONCLUSION}

The paper is a correlation analysis between soil nutrient and chemical composition of the tobacco sample in Yunnan seven tobacco growing areas, discussing the correlation between each index. Principal component analysis was used on the impact factor of chemical composition of flue-cured tobacco, reducing the dimension of the sample space and eliminates autocorrelation between the input variables, stepwise regression analysis was used to established the equation between soil nutrients and tobacco chemical components. Results show that the model in a certain extent, can be based on the results of the determination of soil nutrient quality of Yunnan flue-cured tobacco smoke area prediction, it plays an important role for cultivating high quality tobacco leaves.

\section{ACKNOWLEDGMENT}

Jiande $\mathrm{Wu}$ is corresponding author. This work is supported by the National Natural Science Founder of China (51169007), Science \& Research Program of Yunnan province (2011CI017, 2011DA005, 2012CA022).

\section{REFERENCES}

[1] Jie Chen, Yuanju Tang. "Analysis of Soil Nutrients Affecting Chemical Constituents of Tobacco in Guizhou," Crops, pp. 68-70, January 2008.

[2] Zicheng Xu, Hanqian Xiao, Xianzhang Zhao. "Statistical Methods for Evaluating the Status of Soil Fertility in Tobacco-growing Areas, ” Chinese Journal of Soil Science, vol. 5,2004, pp. 32-35.

[3] Xia Ni, Weikun Lu, Hongbo Cha. "Research Progress of the Effects of Ecological Factors on the Leaf Chemical Components of Tobacco,” Journal of Anhui Agri.Sci. vol. 40, 2012, pp.1355-1359.

[4] Xinmiao Tang, Feng Wang, Chunmei Ji. "Study on the Relationship of Soil Nutrient and Tobacco Chemical Components in Guizhou Province, ”Journal of Henan Agricultural Science, vol. 40,2011, pp.84-88.

[5] Yongan Chen, Yagang Zhu, Jiabo Chen. "Discussion on the Relation between Ecological Factors and Some Chemical Components in Fluecured Tobacco, ” Journal of Anhui Agri.Sci. vol.35, 2007.

[6] Song Qin, Dacui Liu, Jing Liu. "Influence of Soil Fertility on Tobacco Chemical Components and Quality, " Chinese Journal of Soil Science, vol.38, 2007, pp. 901-905.

[7] Lei Wang. "Regression forecast model of support vector machine based on principal component analysis," Information Techn-ology, vol.12, 2008, pp. 58-60.

[8] Yanyan Li, Zicheng Xu, Jinping Wang. "Relationship between Sugar Contents in Flue- cured Tobacco Leaves and Soil Nutrients in Tobacco- growing Areas in Hunan,"Chinese Journal of Soil Science, vol.38, 2007, pp. 911-914.

[9] Keyu Yan, Xianzhang Zhao. Tobacco Classification, Beijing:CHINA AGRICULTURE PRESS, 2003, pp. 22-23. 